Nursing philosophy/Nursing theory

\title{
Nursing Philosophy: Rethinking Nurses' Moral Dilemma and Self-cultivation from the Perspectives of Foucauldian Notions
}

\author{
Koh, Eun Kang \\ Associate Professor, School of Liberal Arts, Seoul National University of Science and Technology, Seoul, Korea
}

\begin{abstract}
Purpose: This article discusses nurses' moral dilemma and self-cultivation from the Foucauldian viewpoint. Methods: The philosophical inquiry approach is utilized to analyze the nurses' moral distress. Analyses are based on Foucauldian perspectives. Results: Foucault's codes of conduct comprising the mode of subjection and telos are discussed to explain nurses' moral dilemma. The dual process of caring is also discussed. Conclusion: From dilemmatic experience, nurses practice self-formation or self-cultivation to become more virtuous, well-balanced, or integrated people. Such characteristics form the essence of nursing practice.
\end{abstract}

Key Words: Nursing philosophy, Foucault, Moral dilemma

\section{INTRODUCTION}

Nurses experience both frustration and moral dilemma in conflict situations. The moral dilemma lies in two opposing moral values. The moral dilemma sometimes occurs between the advocacy of patients and an obligation to follow a physician's order. ${ }^{1)}$ In most cases, two moral values are compatible and escalate each other. The better nurses cooperate with physicians, the more they devote themselves to patients' care. The moral dilemma only occurs in conflict situations. When nurses come across a physician's order that is not in the patient's best interest, they feel moral conflict. A frequent occurrence is when nurses feel that certain tests and treatments following physicians' orders are unnecessary for the patients. ${ }^{2}$ Less frequently but more seriously, nurses may face an illegal situation regarding the physician's order. Two different codes of conduct are given to the nurse in such conflicts: follow the physician's order as a faithful partner of said physician, or file a formal report to the upper governing body as a faithful advocate of patients.

Faithfulness and professionalism, two crucial characteristics of the nursing profession, are not critical to han- dling this moral dilemma. "Faithful to whom" is more critical than "faithfulness" itself. Which is more critical to evaluate "a good nurse"? Nurses' moral dilemma is considered a form of distress. ${ }^{2)}$ Nevertheless, in this article, moral dilemma is discussed as a way in which nurses achieve self-cultivation based on Foucauldian notions.

One of the multiple patterns of knowing in the early nursing literature was "personal knowledge and knowing", which stressed "a virtuous person" and "a well-balanced, integrated personality". 3) Self-cultivation of the nurse was also considered an essential factor in the nursing field by nursing theorists such as Jean Watson. ${ }^{4}$ However, personal knowledge and knowing, or integrated personality of the nurse are more generally considered products of nursing history and rarely a current nursing issue. Various philosophical perspectives influence contemporary nursing and provide diverse views on nursing phenomena. Nursing is the academic discipline in which different philosophical traditions come together to create valuable, synergistic results to overcome the limitations of an individual academic discipline. Michel Foucault (1926 1984) was a French postmodern philosopher, who had a significant impact on the nursing discipline and profession. ${ }^{5)}$ Several concepts

Corresponding author: Koh, Eun Kang

School of Liberal Arts, Seoul National University of Science and Technology, 232 Gongneung-ro, Nowon-gu, Seoul 01811, Korea.

Tel: +82-2-970-6256, Fax: +82-2-978-0573, E-mail: eunkangkoh@seoultech.ac.kr

투고일 2015년 9월 24일 / 심사완료일 2015년 9월 30일 / 게재확정일 2015년 9월 30일 
of Foucault provide useful ways to view the relationships between nurses and the individuals they care for. Foucauldian notions may suggest a new interpretation of "self-cultivation" in providing care.

This article focuses on reinterpreting nurses' moral dilemma and self-cultivation from the Foucauldian viewpoint. To understand the meaning of "self-cultivation" or "self-discipline" in the context of interpersonal relationships from Foucauldian notions could offer an opportunity to revisit the essence of nursing, or "personal knowledge and knowing." Regarding "personal knowledge and knowing", Chinn and Kramer summarized that "a whole host of personal attributes that go beyond virtuous behavior, including self-discipline, knowledge of self, and an openness to the processes of reflection in order to create actions with integrity, are basic to good nursing care".".

\section{The Use of Moral Dilemma}

The moral dilemma experienced by nurses largely derives from the ambiguity of professionalism in nursing. The profession is based on an independent body of knowledge, which enables a professional nurse to independently make decisions in their practice. However, most environments in which most professional nurses work do not allow nurses to fully implement their knowledge for their practices based on their own decision-making. In most nursing applications, nurses are situated in a position dependent on physicians. Physicians' orders are often beyond nurses' own decisionmaking based on their professional knowledge. In short, a professional nurse educated under the independent discipline of nursing ought to depend on doctors' orders in their daily activities.

Conflicts between physicians and nurses are part of the nature of the nursing profession. However, conflicts are not directly related to the dilemmatic situation. If the ambiguity of professionalism did not exist, conflicts would be resolved without causing dilemmatic situations. It is significant that dilemmatic situations occur only among nurses, not physicians. This is because physicians' professionalism is less affected by ambiguity in comparison. In conflicts, physicians may experience anger and irritation, however, nurses experience frustration and loss of self-esteem.

The moral dilemma can be used for nurses practicing the self. On an individual level, a nurse uses a dilemmatic situation for practicing the self and self-construction. They have an opportunity to become the person they want to be, who masters self-control and know-how to enjoy the art of life in their profession. On a group level, nurses construct their identity by resolving the moral dilemma. It is ironic that the use of moral dilemma for identity construction is actually handling the moral dilemma.

The use of moral dilemma in practicing the self is the way of preserving the dilemmatic position as the source of uniqueness in nursing. Nurses should make the best use of the dilemmatic situation as a unique ground of the nursing practice.

\section{Nursing Ethics based on Foucault}

In Foucault's terminology, an individual forms themselves by practicing the self. This is the process of self-cultivation. However, an individual is captured in a power-knowledge system, in which power is exercised in the form of knowledge. ${ }^{6,7)}$

A nurse experiences power-knowledge controlling their behavior. Physicians' orders are a form of power-knowledge that they cannot simply ignore or refuse. When conflicts occur between physicians and nurses, physicians do not regard conflicts as dilemmatic situations; however, nurses do. In conflict, a nurse feels two separate bodies of knowledge and different codes of conduct confront each other: nursing versus medicine, or "make decisions for patients' good" versus "follow physicians' orders". The moral dilemma is summarized as follows: to follow their own assessment as a professional nurse, or to obey physicians' decisions.

In dilemmatic situations, a nurse can use the moral dilemma to practice self-control, improve self-esteem, enlarge their capacity for work, and become an ideal person. In Foucault's view, the process of a nurse cultivating themselves is called ethics. A nurse's ethics functions between codes of conduct and the actual practice of nursing. Unless a nurse is a robot, they should make several decisions to transfer codes of conduct into actual behavior. Foucault divides those decisions into four categories.

First, because they are in a dilemmatic situation, their potential for decision-making and sense of balance can be realized. Between two incompatible codes of conduct in nurses' professionalism, they practice how to drive reconciliation from the contradiction, how to coordinate the conflict situation, and how to deliver the most appropriate decision for the patient among different opinions. The mechanical transformation of the given codes of conduct to behavior cannot be the best way for the person to become a good nurse or successful per- 
son. They can make broad use of the moral dilemma to become who they want to be, similar to a cook using various ingredients to create their desired taste in the food.

Second, a nurse makes a decision on their mode of subjection. They may decide to obey all kinds of codes of conduct given to them without any criticism. In this case, physicians' orders may be the first priority, or an independent nursing assessment may be the most important code of conduct. Criticism can be another mode of subjection. A nurse decides to critically consider any code of conduct given to them. Critical thinking is essential for freedom of thought.

Third, ethical work is required. A nurse decides what techniques should be developed. If a nurse decides to be obedient to codes of conduct, they prioritize among conflicting codes and constantly seek to internalize the codes of conduct. Perfect internalization of codes of conduct is appreciated and can be regarded as a form of mastery of nursing. If a nurse decides to be critical., they may need extra education and constant learning to improve their knowledge. In the power-knowledge system of health care, an individual nurse should manipulate nursing as an independent body of knowledge to exercise their freedom for nursing assessment.

Lastly, telos, which asks what mode of being or way of life constitutes the goal of work, ${ }^{8)}$ is significant in the whole scheme of practicing the self in a dilemmatic situation. An individual thinks about telos in their life. Telos is not simply a job or an income, but also certain values like kindness, honesty, and patience. The working environment is one primary area in which individuals crafts themselves. By working, they may become a rich kind of energetic gentleman, a patient open-minded leader, or a short-tempered workaholic afflicted by anxiety. Self-formation or self-cultivation through work can be done unconsciously and achieved with constant effort. Nursing is a profession involving an individual's personality in their work performance. Resolving a moral dilemma provides an especially good opportunity for a nurse to practice control power over the situation and themselves. The more a nurse masters the technique of self-control, the better they control conflicts and moral dilemma. The ability to resolve conflicts is also exercised in other practices of nursing.

\section{Self-cultivation: The Dual Process of Caring}

In terms of Foucault's ethics, care does not only mean "taking care of others", but it also refers to "taking care of oneself". The ancient Greeks' assumption that the ability and techniques of self-cultivation are connected to taking care of others provides insight on rethinking the concept of care in two ways: taking care of others and oneself. The duality of care in Foucauldian ethics provides scholars with a different perspective of evaluating nursing essentials. Nursing does not simply represent one way of care-giving and care-taking. As nursing essentials, "self-cultivation" and "self-discipline" are presented as bases of care-giving in the Foucauldian perspective.

Nursing involves a dual process of caring: "a care-giver" who takes care of "a care-taker" helps the latter to become the former's ideal state of being and tries to cultivate themselves ("the care-giver") into becoming a good person. This notion corresponds with the early nursing articles on ethical knowing suggesting "the good person to do the right thing" ${ }^{3)}$ In this interpretation, the definition of nursing is taken in its most fundamental sense: caring for a person including the "care-giver" and "care-taker".

\section{CONCLUSION}

Nursing is a profession allowing a person to be in an appropriate position of practicing the self as a way of achieving freedom for the art of life. Nurses have to handle moral dilemmas between formal treatment according to a working manual and informal care based on a person-to-person relationship; and between physicians' orders and nurses' intervention. In a given time and condition, formal treatment based on a manual and order may provide more time and less stress for nurses than nurses' intervention based on their own decision and responsibility.

The nurses' moral dilemma lies in their professionalism based on informality as well as formality. A nurse is a professional who provides care for patients. Care must be holistic: it covers the formal to informal., non-human to human, and amoral to moral., Nursing intervention relies on the balance between the position of care-givers and care-receivers. The moral dilemma that nurses experience in their everyday working environment guides them to mastering and crafting the self. This is the active definition of a nurse's freedom.

Nursing is a unique profession that is identified by its special position and skill in resolving moral dilemmas in health care. If nursing intervention is released from the moral dilemmas and if a nurse does not have to experience dilemmatic situations, nursing may lose the profound basis of its own identity, and nurses may no lon- 
ger experience the pleasure of exercising the art of life. Moreover, from dilemmatic experience, nurses practice self-formation or self-cultivation to become more virtuous, well-balanced, and integrated people. These characteristics form the essence of nursing practice.

\section{REFERENCES}

1. Ahern K, McDonald S. The beliefs of nurses who were involved in a whistleblowing event. J Adv Nurs. 2002;38(3):303-9. http://dx.doi.org/10.1046/j.1365-2648.2002.02180.x

2. Zuzelo PR. Exploring the moral distress of registered nurses. Nurs Ethics. 2007;14(3):344-59.

http://dx.doi.org/10.1177/0969733007075870
3. Chinn PL, Kramer MK. Integrated theory and knowledge development in nursing. 7th ed. St Louis: Mosby; 2008.

4. Tomey AM, Alligood MR. Nursing theorists and their work. St. Louis: Mosby; 2006.

5. Gastaldo D, Holmes D. Foucault and nursing: a history of the present. Nurs Inq. 1999;6(4):231-40. http://dx.doi.org/10.1046/j.1440-1800.1999.00042.x

6. Faubion J. Michel Foucault: power. New York: The News Press; 2000.

7. Rabinow P. Michel Foucault: ethics. New York: The News Press; 1997.

8. O'Leary T. Foucault and the art of ethics. London: Continuum; 2002. 